\title{
Assessing Customer Satisfaction of Urban Rail Transit Network in Tianjin Based on Intuitionistic Fuzzy Group Decision Model
}

\author{
Yuning Wang $\left(\mathbb{D},{ }^{1}\right.$ Zhe Zhang $(\mathbb{D})^{2}$ and Hui Sun $\mathbb{D}^{3}$ \\ ${ }^{1}$ School of Geographic and Environmental Sciences, Tianjin Normal University, Tianjin, China \\ ${ }^{2}$ Sydney School of Architecture, Design and Planning, University of Sydney, NSW, Australia \\ ${ }^{3}$ School of Management and Economics, Tianjin University, Tianjin, China \\ Correspondence should be addressed to Hui Sun; sunhui@tju.edu.cn
}

Received 2 May 2018; Revised 7 July 2018; Accepted 24 October 2018; Published 2 December 2018

Academic Editor: Alicia Cordero

Copyright (C) 2018 Yuning Wang et al. This is an open access article distributed under the Creative Commons Attribution License, which permits unrestricted use, distribution, and reproduction in any medium, provided the original work is properly cited.

\begin{abstract}
Urban rail transit has played an important role in big and crowded cities. Providing services with high levels of customer satisfaction is essential in order to increase the sharing rate of urban rail transit and to reduce traffic congestion by shifting people away from private car use. Therefore, it is of great significance to improve the customer satisfaction of urban rail transit. This paper presents an intuitionistic fuzzy group decision model to evaluate the customer satisfaction of urban rail transit. An evaluation indicator system including seven categories of indicators is established to measure passengers' satisfaction. The overall customer satisfaction level of the urban rail transit lines is obtained by the intuitionistic fuzzy entropy and intuitionistic fuzzy weighted average (IFWA) operator. The intuitionistic fuzzy entropy is used to solve attribute weights and IFWA operator is used to solve the information aggregation. Drawing on Tianjin urban rail transit lines as a case study, the detailed analyses were conducted to evaluate the overall customer satisfaction level of five urban rail transit lines and as such suggesting remedy strategies. The results can help urban rail transit operation company to improve the service quality of urban rail transit.
\end{abstract}

\section{Introduction}

With the acceleration of China's urbanization process, industrial development, and an increased vehicle population, energy consumption and greenhouse gas emissions are threatening the sustainable development of cities. Therefore, reducing the demand for private cars is a key sustainability method. Currently, many mega cities in China are experiencing traffic congestion. In Beijing, the capital of China, the average commuting time increased significantly, from 38 minutes in 2005 to 97 minutes in 2015. To solve this problem, the government tried to attract people to use public transport and implemented some potential solutions. These methods include constructing road networks and public transportation systems and strategies (usually policy-related) that aim to influence tourism demand.

Many authorities and researchers thought that urban rail transit is one of the most important types of public transport [1]. It is considered to be a green, energy-saving, viable alternative to the use of private cars. For the individual, however, car travel is appealing. It is more comfortable, flexible, and private than public transport. At this point, it is very important to improve the service quality of urban rail transit. If the quality of urban rail transit is not good, car drivers will be more reluctant to shift modes, and more congestion will occur. Therefore, improving the quality of urban rail transit services can effectively reduce the number of people using cars to travel and thus benefit all passengers [2]. In order to increase the sharing rate of urban rail transit, it is necessary to evaluate the satisfaction of its services by the service provider. Customer satisfaction assessment has received full attention [3]. However, in practical customer satisfaction evaluation, the uncertainty and ambiguity of customer's subjective feelings and experience in the decisionmaking process make it difficult for them to accurately judge on particular aspects. Therefore, the customer satisfaction evaluation is a fuzzy multi-indicator group decision-making problem.

Since Atanassov (1986) proposed the concept of intuitionistic fuzziness, it has been widely used in pattern recognition, 
market forecasting, etc. and has achieved remarkable effect [4]. Based on this, this paper intends to apply the intuitionistic fuzzy group decision model to the customer satisfaction evaluation of urban rail transit.

The structure of this paper is as follows. The second section summarizes the related literature of public transport and establishes the criteria of customer satisfaction. The third section proposes an integration method based on the intuitionistic fuzzy group decision model. In the fourth section, a case study is provided to discuss the customer satisfaction for Tianjin urban rail transit; the fifth section is the conclusion of this paper.

\section{Literature Review}

2.1. Customer Satisfaction in Public Transportation. Customer satisfaction is a perceived response to the overall emotional response between the expected performance and perceived performance. It is an assessment of the experience after the customer has purchased the product or used the service. In recent years, customer satisfaction in public transport has become a hot topic for researchers [1]. Friman and Gärling (2001) conducted theoretical and empirical analysis of customer satisfaction in public transport services. And they found that the cumulative overall and attribute-specific satisfaction had a positive impact on customer satisfaction [5]. Morfoulaki et al. (2007) defined customer satisfaction as the overall level of customer expectations. They measured customer satisfaction as a percentage of customer expectations [6]. Tyrinopoulos and Antonio (2008) used factor analysis and ordered logit models to evaluate the quality impact on the user, with an emphasis on the passengers' perception of transitivity between operators, and the policy implications of this difference [7]. Geetika (2010) used a factor analysis model to determine the main factors affecting railway service quality and customer satisfaction. The results show that refreshing and behavioral factors are the most important factors affecting passenger satisfaction on railway [8]. Castillo and Benitez (2012) proposed a way to determine and quantify the relationship between ratings that gives overall satisfaction to public transport [9]. Diana (2012) studied the satisfaction of multimodal passengers for local bus services in different cities. The results showed that, in larger cities, bus lines are more competitive on realistic elements [10]. Celik et al. (2014) proposed a new framework, including SERVQUAL, statistical analysis, and VIKOR methods, to evaluate customer satisfaction in the Istanbul rail transit network [11]. Machado-León et al. (2017) take the railway of Algiers as an example, and they proposed a new important performance analysis and decision tree model to analyze the performance changes of the rail service [12]. de Oña et al. (2015) used the method of classification and regression tree to analyze different perceptions among different groups of passengers of transit service [13]. Fu et al. (2017) proposed a matter elements and extension method to evaluate the railway service of Italy; meanwhile, the correlation degree can describe the satisfaction degree of passengers [14]. Eboli et al. (2018) used the passengers' satisfaction survey data to analyze the spatial component in the evaluation of transit service quality, and the results showed that there was strong relationship between the single service aspects and the overall service quality from the passengers' perception [15].

In order to accurately assess the customer satisfaction of rail transit, it is necessary to quantify the factors which influence the customer satisfaction. Eboli and Mazzulla (2014) used rail lines in Northern Italy as a case study; they used SEM method to analyze how passengers perceive satisfaction with service quality [16]. Agarwall (2008) took railway of Indian as an example, conducting a survey to investigate the customer satisfaction. The results showed that behavior of employee had a wide range of impacts on customer satisfaction [17]. Cao and Chen (2011) proposed an SEM model to study the relationship among service quality, customer satisfaction, and customer loyalty of Nanjing-Shanghai high-speed rail. The results showed that, in order to improve the customer loyalty and reduce the complaints of customer, the operator needs to improve customer satisfaction [18]. Stuart et al. (2000) applied SEM techniques to verify how different service attributes directly and indirectly influence the passengers' satisfaction of urban rail transit in New York [19]. Chou et al. (2014) used the SEM model to study the relationship among the service quality, customer satisfaction, and customer loyalty of Taiwan's high-speed rail; the results showed that car cleanliness, employees' neat appearance, employee service attitude, air-conditioning comfort, and punctuality have a positive influence on customer satisfaction. Meanwhile, the higher the customer satisfaction, the higher the customer loyalty [20]. Shen et al. (2016) used SEM model to analyze the customer satisfaction of urban rail transit in China; the results showed that the passenger satisfaction index based on the least squares estimation method can effectively evaluate customer satisfaction [21]. Yilmaz and Ari (2016) proposed an SEM model to analyze the relationship between passenger satisfaction and loyalty. The results showed that service quality and corporate image had a positive impact on customer satisfaction, and the customer satisfaction played a key role in increasing passenger loyalty [22].

2.2. Review of the Intuitionistic Fuzzy Analysis. Due to the complexity of decision-making problems, incomplete decision information, and uncertain factors, it is very difficult for decision-makers to evaluate each alternative with real number. Fuzzy sets introduced by Zadeh (1965) have been identified to be suitable to describe this fuzzy information effectively [23]. However, in some practical situations, fuzzy sets cannot provide a comprehensive description of decision information. In order to solve this problem, Atanassov (1986) proposed the concept of intuitionistic fuzzy set (IFS), which not only considered the degree of membership, but also considered the non-membership degree, and allowed a certain degree of hesitation [4]. Due to the flexibility of IFS in dealing with fuzzy information, researchers pay more and more attention to intuitionistic fuzzy multiattribute decisionmaking (MADM) problems [24-28].

The core issue of MADM is how to effectively aggregate decision-making information. Therefore, many researchers 
have proposed many intuitionistic fuzzy information aggregation operators. $\mathrm{Xu}$ and $\mathrm{Da}$ [29] developed an ordered weighted geometric averaging operator. $\mathrm{Xu}$ and Yager [30] proposed several geometric aggregation operators which are based on intuitionistic fuzzy sets. Liu and Wang [31] developed some intuitionistic fuzzy aggregation operators which are based on Einstein operations.

Although scholars have conducted researches of customer satisfaction for many years, it is still difficult to accurately measure customer satisfaction of urban rail transit. Obviously, the above aggregation operators had the flexibility to handle the vagueness information. Therefore, in this paper, a fuzzy MCDM method is proposed based on intuitionistic fuzzy method to analyze the customer satisfaction in Tianjin's urban rail transit lines.

\section{Methodology}

The basic concepts of intuitionistic fuzzy set and decision model are briefly reviewed, which are foundations of the intuitionistic fuzzy number model to evaluate the customer satisfaction.

\subsection{Basic Concepts and Definitions}

Definition 1. Let $X$ be a nonempty set; an intuitionistic fuzzy set (IFS) can be expressed by

$$
A=\left\{\left\langle x, \mu_{A}(x), v_{A}(x)\right\rangle \mid x \in X\right\}
$$

where $\mu_{A}: X \longrightarrow[0,1], x \in X \longrightarrow \mu_{A}(x) \in[0,1]$, the number of $\mu_{A}(x)$ denotes the membership degree, $v_{A}: X \longrightarrow$ $[0,1], x \in X \longrightarrow v_{A}(x) \in[0,1]$, the number of $v_{A}(x)$ denotes the nonmembership degree, with the condition $0 \leq \mu_{A}(x)+$ $v_{A}(x) \leq 1$ for every $x \in X$. For compute facilitate, we use $\alpha=\left(\mu_{\alpha}, v_{\alpha}\right)$ to represent the intuitionistic fuzzy number [4].

Definition 2. Let $\alpha_{1}=\left(\mu_{\alpha_{1}}, \nu_{\alpha_{1}}\right)$ and $\alpha_{2}=\left(\mu_{\alpha_{2}}, \nu_{\alpha_{2}}\right)$ be two random intuitionistic fuzzy numbers, the score function of $\alpha_{1}$ and $\alpha_{2}$ is represented by $s\left(\alpha_{1}\right)=\mu_{\alpha_{1}}-\nu_{\alpha_{1}}$ and $s\left(\alpha_{2}\right)=$ $\mu_{\alpha_{2}}-v_{\alpha_{2}}$, and the accurate function of $\alpha_{1}$ and $\alpha_{2}$ is represented by $h\left(\alpha_{1}\right)=\mu_{\alpha_{1}}+\nu_{\alpha_{1}}$ and $h\left(\alpha_{2}\right)=\mu_{\alpha_{2}}+\nu_{\alpha_{2}}$; thus

(1) if $s\left(\alpha_{1}\right)<s\left(\alpha_{2}\right)$, then $\alpha_{1}<\alpha_{2}$;

(2) if $s\left(\alpha_{1}\right)=s\left(\alpha_{2}\right)$ and $h\left(\alpha_{1}\right)=h\left(\alpha_{2}\right)$, then $\alpha_{1}=\alpha_{2}$; if $s\left(\alpha_{1}\right)=s\left(\alpha_{2}\right)$ and $h\left(\alpha_{1}\right)<h\left(\alpha_{2}\right)$, then $\alpha_{1}<\alpha_{2}$; if $s\left(\alpha_{1}\right)=s\left(\alpha_{2}\right)$ and $h\left(\alpha_{1}\right)>h\left(\alpha_{2}\right)$, then $\alpha_{1}>\alpha_{2}$ [36].

Definition 3. Let $\alpha_{j}=\left(\mu_{\alpha_{j}}, v_{\alpha_{j}}\right),(j=1,2, \cdots, n)$ be a group of intuitionistic fuzzy numbers; the IFWA operator can be defined as follows [38]:

$$
\begin{aligned}
& \operatorname{IFWA}_{\omega}\left(\alpha_{1}, \alpha_{2}, \cdots, \alpha_{n}\right)=\omega_{1} \alpha_{1} \oplus \omega_{2} \alpha_{2} \oplus \cdots \oplus \omega_{n} \alpha_{n} \\
& \quad=\left(1-\prod_{j=1}^{n}\left(1-\mu_{\alpha_{j}}\right)^{\omega_{j}}, \prod_{j=1}^{n} \nu_{\alpha_{j}}^{\omega_{j}}\right)
\end{aligned}
$$

where $\omega=\left(\omega_{1}, \omega_{2}, \cdots \omega_{n}\right)^{T}$ is the attribute weight vector of $\alpha_{j}(j=1,2, \cdots, n), \omega_{j} \in[0,1], \sum_{j=1}^{n} \omega_{j}=1$.
Definition 4. Let $H: A \longrightarrow[0,1]$ be the entropy of the IFS $A=\left\{\left\langle x, \mu_{A}(x), v_{A}(x)\right\rangle \mid x \in X\right\}$ [39], and it can be calculated by

$$
\begin{gathered}
H(A)=-\frac{1}{n \ln 2} \sum_{i=1}^{n}\left[\mu_{A}(x) \ln \mu_{A}(x)+\nu_{A}(x) \ln \nu_{A}(x)\right. \\
\left.-\left(1-\pi_{A}(x)\right) \times \ln \left(1-\pi_{A}(x)\right)-\pi_{A}(x) \ln 2\right]
\end{gathered}
$$

3.2. Description of the Decision Model. $D=\left\{d_{1}, d_{2}, \cdots, d_{l}\right\}$ represents the expert set, $X=\left\{x_{1}, x_{2}, \cdots, x_{m}\right\}$ represents the alternative set, and $C=\left\{c_{1}, c_{2}, \cdots, c_{n}\right\}$ represents the attributes set. The weight vector of the customers is represented by $\xi=\left(\xi_{1}, \xi_{2}, \cdots, \xi_{l}\right)^{T}, 0 \leq \xi_{k} \leq 1, k=$ $1,2, \cdots, l, \sum_{k=1}^{l} \xi_{k}=1$. And the weight vector of the attributes is represented by $\omega=\left(\omega_{1}, \omega_{2}, \cdots \omega_{n}\right)^{T}, 0 \leq \omega_{j} \leq$ $1, j=1,2, \cdots n, \sum_{j=1}^{n} \omega_{j}=1 . A_{k}=\left(\left(\mu_{a_{i j}^{k}}, v_{a_{i j}^{k}}\right)\right)_{m \times n}$ is the intuitionistic fuzzy decision matrix by customer $d_{k}{ }^{\prime} s$ evaluated $x_{i}$ under $c_{j}$.

The evaluation framework mainly includes five steps.

Step 1 (normalization of the decision attributes). In this study, attributes contain both benefit-focused and cost-focused types. Accordingly, we had to normalize the cost-focused type to the benefit-focused type. In accordance with Liu et al. [40], this paper uses (4) to transform $A_{k}=\left(a_{i j}^{k}\right)_{m \times n}$ into $R_{k}=\left(r_{i j}^{k}\right)_{m \times n}$, where

$$
\begin{aligned}
r_{i j}^{k} & =\left(\mu_{r_{i j}^{k}}, v_{r_{i j}^{k}}\right) \\
& =\left\{\begin{array}{ll}
a_{i j}^{k}, & c_{j} \text { is the benefit-focused type attribute } \\
\bar{a}_{i j}^{k} & c_{j} \text { is the cost-focused type attribute }
\end{array}\right\}
\end{aligned}
$$

and $\bar{a}_{i j}^{k}=\left(v_{a_{i j}^{k}}, \mu_{a_{i j}^{k}}\right), k=1,2, \cdots l, i=1,2, \cdots m, j=$ $1,2, \cdots n$

$$
R_{k}=\left(\begin{array}{ccc}
\left(\mu_{r_{11}^{k}}, v_{r_{11}^{k}}\right) & \cdots & \left(\mu_{r_{1 n}^{k}}, v_{r_{1 n}^{k}}\right) \\
\vdots & \ddots & \vdots \\
\left(\mu_{r_{m 1}^{k}}, \nu_{r_{m 1}^{k}}\right) & \cdots & \left(\mu_{r_{m n}^{k}}, \nu_{r_{m n}^{k}}\right)
\end{array}\right)
$$

Step 2 (transformation of the intuitionistic fuzzy decision matrix). We extract the $i$-line data from normalized intuitionistic fuzzy decision matrix $R_{k}$ and let $T_{i}=$ $\left(\left(\mu_{\mu_{i j}^{k}}, v_{\mu_{i j}^{k}}\right)\right)_{l \times n}(i=1,2, \cdots, m, j=1,2, \cdots, n, k=$ $1,2, \cdots, l)$ be a new matrix, and it represents the decision matrix of all customers evaluating the $i$ th alternative on the basis of the $n$ attributes.

$$
T_{i}=\left(\begin{array}{ccc}
\left(\mu_{\mu_{i 1}^{1}}, \nu_{\mu_{i 1}^{1}}\right) & \cdots & \left(\mu_{\mu_{i n}^{1}}, \nu_{\mu_{i n}^{1}}\right) \\
\vdots & \ddots & \vdots \\
\left(\mu_{\mu_{i 1}^{l}}, \nu_{\mu_{i 1}^{l}}\right) & \cdots & \left(\mu_{\mu_{i n}^{l}}, \nu_{\mu_{i n}^{l}}\right)
\end{array}\right)
$$


Step 3 (using the intuitionistic fuzzy entropy to determine the optimal weights for each attribute). By using (3), we can get the entropies for each attribute. Following the concept of intuitionistic fuzzy entropy method, the entropy weights can be got by

$$
\begin{aligned}
H_{j}^{i} & =-\frac{1}{l \ln 2} \sum_{k=1}^{l}\left[\mu_{r_{i j}^{k}}(x) \ln \mu_{r_{i j}^{k}}(x)+\nu_{r_{i j}^{k}}(x) \ln \nu_{r_{i j}^{k}}(x)\right. \\
& \left.-\left(1-\pi_{r_{i j}^{k}}(x)\right) \times \ln \left(1-\pi_{r_{i j}^{k}}(x)\right)-\pi_{r_{i j}^{k}}(x) \ln 2\right] \\
\omega_{j}^{i} & =\frac{1-H_{j}^{i}}{n-\sum_{j=1}^{n} H_{j}^{i}}
\end{aligned}
$$

After obtaining the entropy weight of each attribute, then the optimal weight $\omega^{*}=\left(\omega_{1}^{*}, \omega_{2}^{*}, \cdots \omega_{n}^{*}\right)^{T}$ can be got,

$$
\omega_{j}^{*}=\frac{\prod_{i=1}^{m} \omega_{j}^{i}}{\sum_{j=1}^{n} \prod_{i=1}^{m} \omega_{j}^{i}}
$$

Step 4 (aggregate the alternatives by IFWA operator). After obtaining the optimal weight $\omega^{*}=\left(\omega_{1}^{*}, \omega_{2}^{*}, \cdots \omega_{n}^{*}\right)^{T}$, we use the IFWA operator to aggregate the alternative $x_{i}$; then the individual evaluation result $y_{k i}$ of customer $d_{k}$ can be got by

$$
\begin{array}{r}
y_{k i}=\bigoplus_{j=1}^{n} r_{i j}^{k} \omega_{j}=\left[1-\prod_{j=1}^{n}\left(1-\mu_{r_{i j}^{k}}\right)^{\omega_{j}}, \prod_{j=1}^{n}\left(v_{r_{i j}^{k}}\right)^{\omega_{j}}\right], \\
i=1,2, \cdots, m ; k=1,2, \cdots l
\end{array}
$$

Step 5 (comprehensive evaluation of customer satisfaction). After obtaining the individual evaluation result $y_{k i}$ by (10), by using the customer weight $\xi=\left(\xi_{1}, \xi_{2}, \cdots, \xi_{l}\right)^{T}$, we can use (11) to get the comprehensive attribute values,

$$
\begin{aligned}
z_{x_{i}} & =\bigoplus_{k=1}^{l} y_{k i} \xi_{k}=(1 \\
& -\prod_{k=1}^{l}\left[1-\left(1-\prod_{j=1}^{n}\left(1-\mu_{r_{i j}^{k}}\right)^{\omega_{j}}\right)\right]^{\xi_{k}}, \\
& \left.\prod_{k=1}^{l}\left[\prod_{j=1}^{n}\left(v_{r_{i j}^{k}}\right)^{\omega_{j}}\right]^{\xi_{k}}\right)
\end{aligned}
$$

At last, we can get the customers' group evaluation result $z_{x_{i}}, i=1,2, \cdots m$, and according to Definition 2 to achieve the final sequence of alternatives.

\section{Case Study}

In this section, we first introduced the basic situation of urban rail transit in Tianjin and customer satisfaction survey data. Then, the proposed method is applied for the processing of customer satisfaction survey questions. Finally, the discussions are conducted.

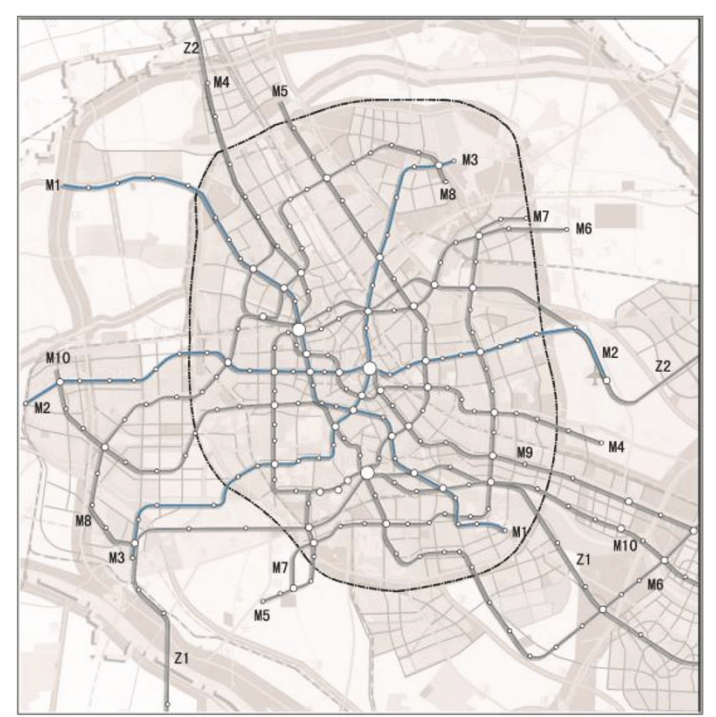

FIGURE 1: The urban rail transit line planning network of Tianjin in 2020.

4.1. Urban Rail Transit System in Tianjin. Tianjin is a municipality directly under the Central Government of China; it is one of the biggest industrial centers in China. According to Tianjin Statistical Institute, Tianjin's population will reach more than 18 million in 2020 . However, with rapid industrial development and an increased vehicle population, traffic congestion and greenhouse gas emissions are threatening the sustainable development of Tianjin. Therefore, the government wants to ameliorate public transport system to alleviate urban problems. Urban rail transit is an effective way to alleviate traffic pressure and traffic pollution. Tianjin is now promoting the construction of urban rail transit system. By the end of 2017, there were 5 operating lines in the central city of Tianjin, and the length of lines exceeds $166 \mathrm{~km}$. The government feels that the length cannot meet the demand of the passengers. Therefore, the government plans to increase the length of lines. In addition, it aims to improve passenger satisfaction.

Tianjin Metro Group Limited Liability Company (Tianjin Metro) operates 5 lines and serves 999,700 passengers a day. According to the plan, by 2020, Tianjin Metro will operate line length to $513 \mathrm{~km}$ (Figure 1).

M1, M2, and M3 constitute the basic skeleton of urban rail transit network in Tianjin. M1 is the first urban rail transit line of Tianjin; it opened in 1984. It serves between Liuyuan and Caijing University. M2 has been put into use since 2012 and the length of it has been extended for 2014. It serves between Caozhuang and Binhai airport. M3 has been in service since 2012 and the length of it has been extended for 2013. It serves between Xiaodian and South railway station. M6 is the newest rail line which is in service since 2016. It serves between Nan sunzhuang and Nan cuiping. M9 is in service since 2004 and the length of it was extended by 2012. It serves between Binhai New District and Tianjin railway station. All of them cover the main public transport corridors of Tianjin. 


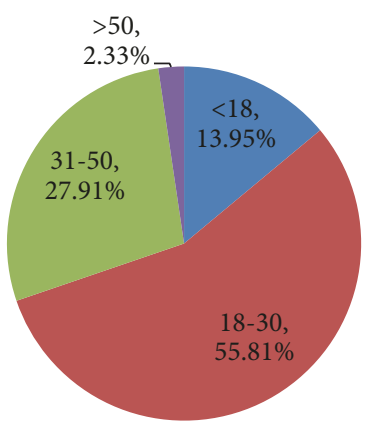

FIGURE 2: Age range.

4.2. Data Acquisition and the Criteria. Five urban rail transit routes (M1, M2, M3, M6, and M9) were investigated in 2017 from October 27 to November 5. A survey questionnaire was designed to measure the existing customer satisfaction level of different lines perceived by passengers. In total 600 surveys were conducted and 564 effective responses were received, and the passengers of each line were asked to assess the satisfaction of the line on each criterion. The survey questionnaire was randomly given face-to-face to both arriving and departing customers.

The surveys consisted of three parts that gathered information related to passengers' perceptions: (1) passengers' sociodemographic characteristics: age, sex, education, job, etc.; (2) use of trains: place of departure and destination, travel time consuming, frequency, and reasons for use, etc.; (3) passengers' perceptions about the level of satisfaction: overall level of satisfaction, stations and the service provided, and criteria based satisfaction. As shown in Figure 2, the most of the survey respondents are 18 30 years old, and the second largest of the survey respondents are 31 50 years old; that is, $97.7 \%$ of the respondents are younger than 50 years of age. As shown in Figure 3, most of the passengers go to the station by walking; meanwhile, $21.63 \%$ of them ride bicycle; this is because the introduction of bike-sharing schemes, pioneered by companies like Ofo and Mobike, has attracted people to use the bike. In places where the subway does not extend, it is easy to get to the destination that you want to go to with Mobike. Only $4.18 \%$ of the passengers choose their private cars to access to stations. This is because there are few parking lots near the stations. As shown in Figures 4 and 5, 34.88\% of the passengers use the urban rail transit lines every day and $32.56 \%$ of the passengers use the urban rail transit lines occasionally; most of the passengers choose urban rail transit lines for work, school, and shopping.

The customer satisfaction evaluation index has a guiding role for the urban rail transit operators and guides them to improve operational performance and service quality. In this paper, the main and subcriteria used are briefly explained for customer satisfaction survey, as shown in Table 1. Basically users evaluated 7 categories and 20 attributes regarding the following satisfaction aspects: accessibility, ticketing service, information service system, station comfort, train comfort, safety, time, etc. From Table 1, we can see that accessibility contains 3 subcriteria, including access to metro-stations, the

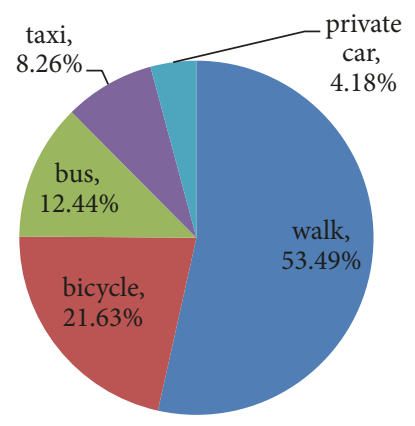

Figure 3: Access type.

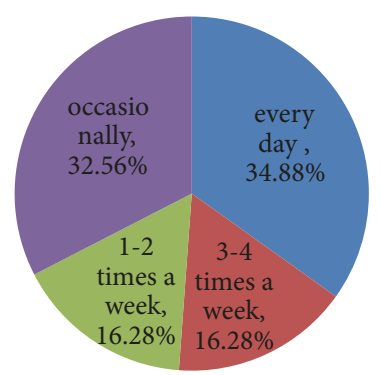

FIGURE 4: Journey frequency.

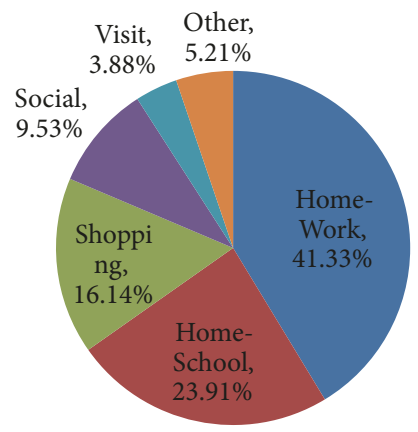

FIgURE 5: Aim of use.

smooth functioning of the tollgate, and access and condition of escalators. All of these criteria had an important effect on train usage rate. Ticketing service contains 2 subcriteria, including vending machines and ticketing system. It ensures passengers' easier access to the station and the loading time decreases. Information service system contains 3 subcriteria, including the usage of modern equipment in station services, the usage of modern equipment inside the train services, and announcements in stations and trains during and after breakdowns. Nathanail (2008) noted that information service system is one of the most important criteria which affect the passenger satisfaction [38]. Station comfort contains 3 subcriteria, including cleanliness of metro stations, lighting of the stations, and comfort level in stations. Train comfort contains 4 subcriteria. If the station and train are clean and comfortable, passengers may feel happy and relaxed. Safety contains 2 subcriteria, including safety at stations and sense of security against accidents while traveling. Passengers value safety as an important criterion; if the train is unsafe, 
passenger will not choose to take it. Time contains 3 subcriteria, including waiting time for metro before departure, journey time, and itinerary accuracy. This criterion values the passenger's perception of the accuracy of departure time, arrival time, and waiting time before departures.

4.3. The Proposed Method Computations. Five passengers are chosen randomly to create the expert set $D=$ $\left(D_{1}, D_{2}, D_{3}, D_{4}, D_{5}\right)$. The weight vectors of the five passengers are equal; that is, $\xi=(0.2,0.2,0.2,0.2,0.2)^{T}$. The alternative set consisting of five lines (M1, M2, M3, M6, and M9) is represented by $\left(X_{1}, X_{2}, X_{3}, X_{4}, X_{5}\right)$. From Table 1 , we can get the attribute set $C=\left\{c_{1}, c_{2}, \cdots, c_{20}\right\}$; it includes 20 evaluation attributes. Then the intuitionistic fuzzy decision matrix $A_{k}=$ $\left(a_{i j}^{k}\right)_{m \times n}(k=1,2, \cdots, 5 ; i=1,2, \cdots, 5 ; j=1,2, \cdots, 20)$ can be got by the evaluation of $d_{k}$. The evaluation procedures of the customer satisfaction are as follows.

(1) Completion of the Intuitionistic Fuzzy Decision Matrix for Customer Satisfaction Evaluation by Passenger Assessment. According to the index system for customer satisfaction of urban rail transit in Table 1, we can establish the intuitionistic fuzzy decision matrix. For example, $A_{1}$ is the intuitionistic fuzzy decision matrix for customer satisfaction evaluation by one passenger.

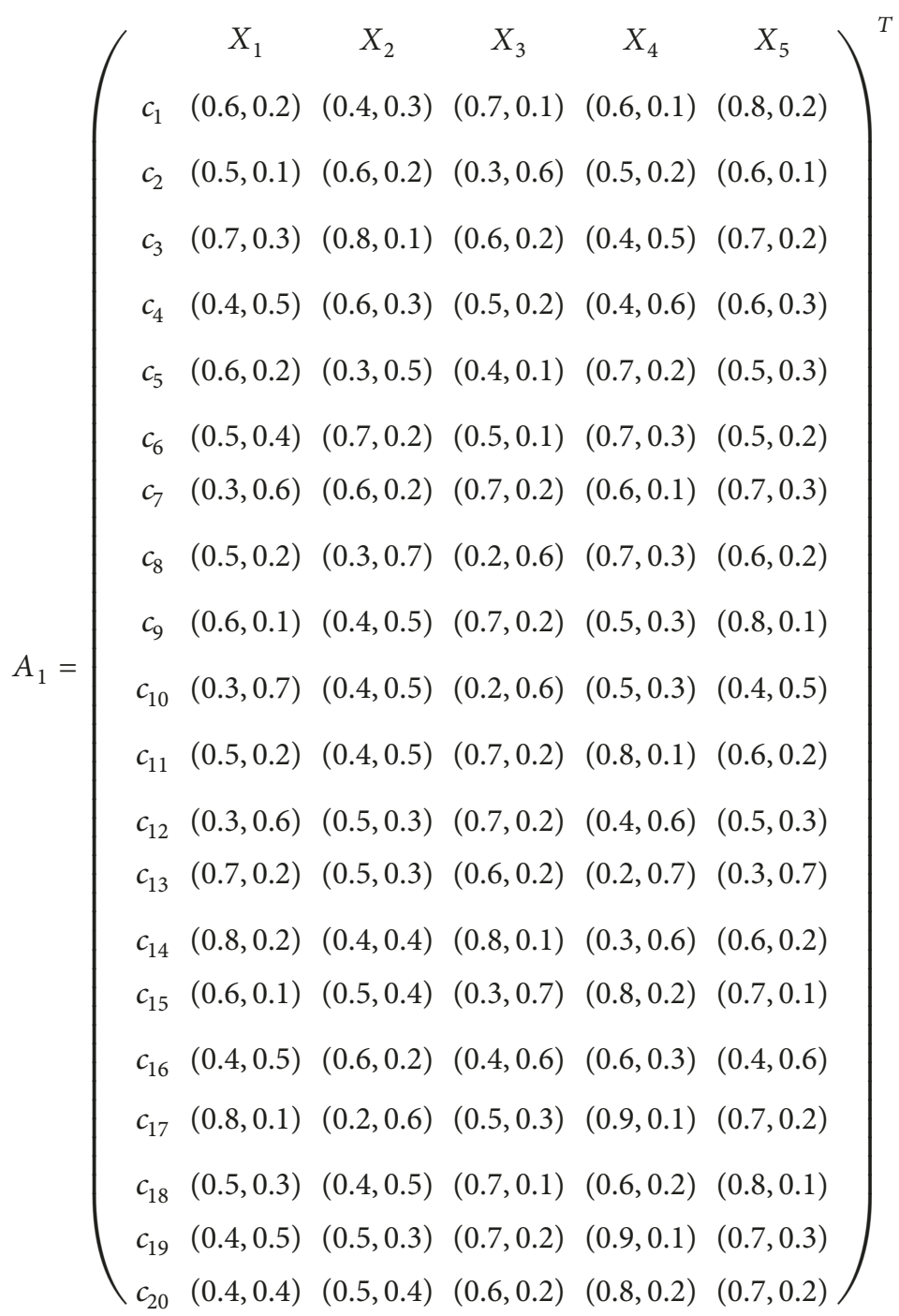

Normalization of the intuitionistic fuzzy decision matrix of passenger evaluation information, where the benefitfocused type includes $C_{j}(j=1,2, \cdots, 12,14,16,17,19,20)$, and the cost-focused type includes $C_{j}(j=13,15,18)$. Therefore, we can use (4) to convert cost-focused type to benefit-focused type.
(2) Convert the Passenger Evaluation Information Decision Matrix into Evaluation Matrix of Rail Transit Lines. After obtaining the five intuitionistic fuzzy matrix, we extract the $i$-line data of the matrix and establish a matrix $T_{i}=\left(\left(\mu_{u_{i j}^{k}}, v_{u_{i j}^{k}}\right)\right)_{5 \times 20}(i=1,2, \cdots, 5 ; j=1,2, \cdots, 20 ; k=$ $1,2, \cdots, 5)$. For example, to evaluate the M1, let 
TABLE 1: Evaluation index for customer satisfaction of urban rail transit.

\begin{tabular}{|c|c|c|}
\hline Factor & Attribute & References \\
\hline \multirow{3}{*}{ Accessibility } & Access to metro stations $(\mathrm{C} 1)$ & Brons et al.[32], de Oña et al.[33] \\
\hline & The smooth functioning of the tollgate (C2) & Aydin et al.[1] \\
\hline & Access and condition of escalators (C3) & Nathanail[34], Brons et al.[32] \\
\hline \multirow{2}{*}{ Ticketing service } & Vending machines (C4) & Vuk[33], Aydin [35] \\
\hline & Ticketing system (C5) & Aydin et al.[1], Geetika [8] \\
\hline \multirow{3}{*}{ Information service system } & The usage of modern equipment in station services (C6) & Aydin et al.[1], Nathanail[34] \\
\hline & The usage of modern equipment inside the train services (C7) & Aydin et al.[1], Machado-León et al.[1 \\
\hline & Announcements in stations and trains during and after breakdowns (C8) & Aydin et al.[1], Litman[2] \\
\hline \multirow{3}{*}{ station comfort } & Cleanliness of metro stations (C9) & de Oña et al.[13] \\
\hline & Lighting of the stations $(\mathrm{C} 10)$ & Aydin et al.[1] \\
\hline & Comfort level in stations (C11) & Aydin et al.[1], Garrido and De[27] \\
\hline \multirow{4}{*}{ train comfort } & Cleanliness inside the trains $(\mathrm{C} 12)$ & Aydin et al.[1], dell'Olio et al.[36] \\
\hline & Noise level and vibration during the journey $(\mathrm{C} 13)$ & Brons et al.[23] \\
\hline & Air-conditioning system inside the trains (C14) & Aydin et al.[1], Geetika [8] \\
\hline & Train crowding $(\mathrm{C} 15)$ & Machado-León et al.[12], Vuk[35] \\
\hline \multirow{2}{*}{ safety } & Safety at stations (C16) & Aydin et al.[1], Nathanail[34] \\
\hline & Sense of security against accidents while traveling (C17) & dell'Olio et al.[13], Aydin [35] \\
\hline \multirow{3}{*}{ time } & Waiting time for metro before departure (C18) & Aydin et al.[1], Gerçek et al.[37] \\
\hline & Journey time (C19) & Shen et al.[21], Yilmaz et al.[22] \\
\hline & Itinerary accuracy $(\mathrm{C} 20)$ & Aydin et al.[1], Chou et al.[20] \\
\hline
\end{tabular}

$T_{1}=\left(\left(\mu_{u_{1 j}^{k}}, v_{u_{1 j}^{k}}\right)\right)_{5 \times 20}$ be a new matrix formed by the first line out of the above 5 intuitionistic fuzzy matrix,

$$
T_{1}=\left(\begin{array}{cccccc} 
& A_{1} & A_{2} & A_{3} & A_{4} & A_{5} \\
c_{1} & (0.6,0.2) & (0.5,0.3) & (0.5,0.2) & (0.8,0.1) & (0.4,0.2) \\
c_{2} & (0.5,0.1) & (0.4,0.4) & (0.7,0.1) & (0.3,0.5) & (0.7,0.1) \\
c_{3} & (0.7,0.3) & (0.7,0.2) & (0.4,0.6) & (0.5,0.5) & (0.2,0.5) \\
c_{4} & (0.4,0.5) & (0.3,0.5) & (0.5,0.2) & (0.6,0.3) & (0.6,0.1) \\
c_{5} & (0.6,0.2) & (0.6,0.2) & (0.4,0.1) & (0.8,0.2) & (0.5,0.3) \\
c_{6} & (0.5,0.4) & (0.3,0.6) & (0.2,0.5) & (0.7,0.3) & (0.6,0.3) \\
c_{7} & (0.3,0.6) & (0.4,0.5) & (0.5,0.3) & (0.6,0.4) & (0.2,0.5) \\
c_{8} & (0.5,0.2) & (0.5,0.4) & (0.3,0.6) & (0.8,0.2) & (0.5,0.3) \\
c_{9} & (0.6,0.1) & (0.6,0.3) & (0.7,0.2) & (0.5,0.4) & (0.3,0.6) \\
c_{10} & (0.3,0.7) & (0.3,0.3) & (0.2,0.7) & (0.4,0.6) & (0.5,0.5) \\
c_{11} & (0.5,0.2) & (0.7,0.2) & (0.5,0.3) & (0.7,0.1) & (0.6,0.2) \\
c_{12} & (0.3,0.6) & (0.4,0.6) & (0.6,0.1) & (0.3,0.6) & (0.4,0.6) \\
c_{13} & (0.2,0.7) & (0.6,0.3) & (0.4,0.4) & (0.3,0.7) & (0.3,0.6) \\
c_{14} & (0.8,0.2) & (0.8,0.1) & (0.7,0.3) & (0.6,0.2) & (0.7,0.2) \\
c_{15} & (0.1,0.6) & (0.4,0.5) & (0.2,0.7) & (0.8,0.2) & (0.1,0.7) \\
c_{16} & (0.4,0.5) & (0.7,0.1) & (0.5,0.5) & (0.7,0.3) & (0.7,0.2) \\
c_{17} & (0.8,0.1) & (0.5,0.3) & (0.4,0.6) & (0.9,0.1) & (0.6,0.4) \\
c_{18} & (0.3,0.5) & (0.2,0.5) & (0.7,0.1) & (0.5,0.4) & (0.6,0.4) \\
c_{19} & (0.4,0.5) & (0.8,0.1) & (0.6,0.4) & (0.8,0.1) & (0.3,0.6) \\
c_{20} & (0.4,0.4) & (0.6,0.3) & (0.7,0.2) & (0.6,0.3) & (0.6,0.4)
\end{array}\right)
$$


(3) Using the Intuitionistic Fuzzy Entropy to Determine the Optimal Weights for Each Attribute. By using (7) to calculate the entropies of the 20 attributes, the results are shown in Table 2. From Table 2, we can get the entropy value of the 20 attributes for the five alternatives. According to Definition 4, the larger the amount of information in the data, the smaller the uncertainty and the entropy value; on the contrary, the entropy value is large.

The entropy weight of the information provided by the passenger under the alternative is obtained according to (8). The results are shown as follows:

$$
\widehat{\omega}=\left(\begin{array}{lllll}
0.058 & 0.057 & 0.059 & 0.065 & 0.047 \\
0.072 & 0.037 & 0.042 & 0.026 & 0.068 \\
0.034 & 0.134 & 0.031 & 0.007 & 0.043 \\
0.037 & 0.046 & 0.034 & 0.047 & 0.023 \\
0.056 & 0.017 & 0.030 & 0.058 & 0.037 \\
0.027 & 0.060 & 0.060 & 0.038 & 0.017 \\
0.018 & 0.020 & 0.037 & 0.035 & 0.019 \\
0.037 & 0.072 & 0.025 & 0.055 & 0.079 \\
0.048 & 0.046 & 0.093 & 0.030 & 0.059 \\
0.027 & 0.039 & 0.019 & 0.041 & 0.042 \\
0.064 & 0.032 & 0.078 & 0.098 & 0.056 \\
0.036 & 0.028 & 0.053 & 0.005 & 0.047 \\
0.035 & 0.084 & 0.015 & 0.060 & 0.034 \\
0.090 & 0.064 & 0.073 & 0.013 & 0.082 \\
0.085 & 0.042 & 0.038 & 0.099 & 0.061 \\
0.052 & 0.092 & 0.023 & 0.014 & 0.069 \\
0.080 & 0.048 & 0.055 & 0.100 & 0.058 \\
0.040 & 0.036 & 0.067 & 0.042 & 0.057 \\
0.075 & 0.029 & 0.074 & 0.091 & 0.050 \\
0.029 & 0.019 & 0.093 & 0.077 & 0.054
\end{array}\right)^{T}
$$

Then, we can get the optimal weights of each attribute according to (9):

$$
\begin{aligned}
& \omega_{1}^{*}=0.0918, \\
& \omega_{2}^{*}=0.0308, \\
& \omega_{3}^{*}=0.0067,
\end{aligned}
$$

$$
\begin{aligned}
& \omega_{4}^{*}=0.0102, \\
& \omega_{5}^{*}=0.0094, \\
& \omega_{6}^{*}=0.0100, \\
& \omega_{7}^{*}=0.0014 \\
& \omega_{8}^{*}=0.0441, \\
& \omega_{9}^{*}=0.0554, \\
& \omega_{10}^{*}=0.0052, \\
& \omega_{11}^{*}=0.1370, \\
& \omega_{12}^{*}=0.0020, \\
& \omega_{13}^{*}=0.0138, \\
& \omega_{14}^{*}=0.0697 \\
& \omega_{15}^{*}=0.1260, \\
& \omega_{16}^{*}=0.0173, \\
& \omega_{17}^{*}=0.1880, \\
& \omega_{18}^{*}=0.0365, \\
& \omega_{19}^{*}=0.1118, \\
& \omega_{20}^{*}=0.0331
\end{aligned}
$$

Based on the evaluations, the weights of the top five subcriteria are determined as follows: sense of security against accidents while traveling (C17), comfort level in stations (C11), train crowding (C15), journey time (C19), and access to metro stations (C1). Also, based on the results, the least important five subcriteria are the usage of modern equipment inside the train services (C7), cleanliness inside the trains (C12), lighting of the stations (C10), access and condition of escalators (C3), and ticketing system (C5).

(4) Aggregate the Alternatives by IFWA Operator. Aggregate all the passenger fuzzy evaluation values under each alternative according to (2), and we can get the comprehensive evaluation matrix $Y_{k i}$ as follows:

$$
Y_{k i}=\left(\begin{array}{cccccc}
D_{1} & D_{2} & D_{3} & D_{4} & D_{5} \\
X_{1} & (0.5685,0.2369) & (0.4045,0.4272) & (0.6201,0.2370) & (0.7254,0.1994) & (0.6227,0.2524) \\
X_{2} & (0.5981,0.2552) & (0.4998,0.2669) & (0.6094,0.2281) & (0.6024,0.2496) & (0.5628,0.3396) \\
X_{3} & (0.5097,0.3532) & (0.5749,0.1936) & (0.5737,0.2627) & (0.5964,0.2329) & (0.5621,0.2726) \\
X_{4} & (0.7630,0.1615) & (0.5205,0.2198) & (0.5809,0.2108) & (0.5839,0.1972) & (0.5173,0.2442) \\
X_{5} & (0.4984,0.3456) & (0.4231,0.4365) & (0.6699,0.2202) & (0.5852,0.3151) & (0.6185,0.2335)
\end{array}\right)
$$


TABLE 2: The entropies of the 20 attributes for the five alternatives.

\begin{tabular}{lcc}
\hline Alternatives & Indicator entropy value \\
\hline M1 & $H_{1}^{1}=0.8441, H_{2}^{1}=0.8047, H_{3}^{1}=0.9088, H_{4}^{1}=0.9001, H_{5}^{1}=0.8489, H_{6}^{1}=0.9216, H_{7}^{1}=0.9512$ \\
& $H_{8}^{1}=0.9016, H_{9}^{1}=0.8694, H_{10}^{1}=0.9280, H_{11}^{1}=0.8279, H_{12}^{1}=0.9018, H_{13}^{1}=0.9044, H_{14}^{1}=0.7586$ \\
& $H_{15}^{1}=0.7701, H_{16}^{1}=0.8592, H_{17}^{1}=0.7855, H_{18}^{1}=0.8931, H_{19}^{1}=0.7991, H_{20}^{1}=0.9223$ \\
M2 & $H_{1}^{2}=0.8673, H_{2}^{2}=0.9132, H_{3}^{2}=0.6852, H_{4}^{2}=0.8914, H_{5}^{2}=0.9608, H_{6}^{2}=0.8596, H_{7}^{2}=0.9536$ \\
& $H_{8}^{2}=0.8317, H_{9}^{2}=0.8928, H_{10}^{2}=0.9086, H_{11}^{2}=0.9245, H_{12}^{2}=0.9344, H_{13}^{2}=0.8026, H_{14}^{2}=0.8493$ \\
& $H_{15}^{2}=0.9017, H_{16}^{2}=0.7845, H_{17}^{2}=0.8879, H_{18}^{2}=0.9148, H_{19}^{2}=0.9328, H_{20}^{2}=0.9556$ \\
M3 & $H_{1}^{3}=0.8343, H_{2}^{3}=0.8816, H_{3}^{3}=0.9142, H_{4}^{3}=0.9037, H_{5}^{3}=0.9163, H_{6}^{3}=0.8311, H_{7}^{3}=0.8960$ \\
& $H_{8}^{3}=0.9303, H_{9}^{3}=0.7412, H_{10}^{3}=0.9478, H_{11}^{3}=0.7808, H_{12}^{3}=0.8531, H_{13}^{3}=0.9588, H_{14}^{3}=0.7971$ \\
M6 & $H_{15}^{3}=0.8942, H_{16}^{3}=0.9346, H_{17}^{3}=0.8474, H_{18}^{3}=0.8114, H_{19}^{3}=0.7918, H_{20}^{3}=0.7388$ \\
& $H_{1}^{4}=0.7905, H_{2}^{4}=0.9168, H_{3}^{4}=0.9765, H_{4}^{4}=0.8474, H_{5}^{4}=0.8119, H_{6}^{4}=0.8759, H_{7}^{4}=0.8873$ \\
M9 & $H_{8}^{4}=0.8231, H_{9}^{4}=0.9041, H_{10}^{4}=0.8675, H_{11}^{4}=0.6820, H_{12}^{4}=0.9836, H_{13}^{4}=0.8061, H_{14}^{4}=0.9576$ \\
& $H_{15}^{4}=0.6803, H_{16}^{4}=0.9539, H_{17}^{4}=0.6747, H_{18}^{4}=0.8636, H_{19}^{4}=0.7052, H_{20}^{4}=0.7492$ \\
$H_{1}^{5}=0.8858, H_{2}^{5}=0.8355, H_{3}^{5}=0.8963, H_{4}^{5}=0.9429, H_{5}^{5}=0.9102, H_{6}^{5}=0.9588, H_{7}^{5}=0.9541$ \\
$H_{8}^{5}=0.8070, H_{9}^{5}=0.8574, H_{10}^{5}=0.8985, H_{11}^{5}=0.8648, H_{12}^{5}=0.8852, H_{13}^{5}=0.9183, H_{14}^{5}=0.8012$ \\
$H_{15}^{5}=0.8527, H_{16}^{5}=0.8313, H_{17}^{5}=0.8592, H_{18}^{5}=0.8607, H_{19}^{5}=0.8795, H_{20}^{5}=0.8690$
\end{tabular}

(5) Comprehensive Ranking of All Lines. According to (11), the comprehensive attribute values of each alternative are obtained. The result is shown as follows:

$$
\begin{aligned}
& z_{x_{1}}=(0.6010,0.0943), \\
& z_{x_{2}}=(0.4885,0.2919), \\
& z_{x_{3}}=(0.6124,0.2311), \\
& z_{x_{4}}=(0.6231,0.2352), \\
& z_{x_{5}}=(0.5785,0.2660) .
\end{aligned}
$$

According to Definition 2, we can get $S\left(z_{x_{1}}\right)=0.5068$, $S\left(z_{x_{2}}\right)=0.1966, S\left(z_{x_{3}}\right)=0.3813, S\left(z_{x_{4}}\right)=0.3879, S\left(z_{x_{5}}\right)=$ 0.3125 . Therefore, $P_{1}>P_{4}>P_{3}>P_{5}>P_{2}$. So, M1 has the best customer satisfaction level.

4.4. Results and Discussion. The study aims to find out the customer satisfaction level of urban rail transit in Tianjin. By using intuitionistic fuzzy group decision model, we got the scores and the sorts the results of customer satisfaction. And the results are discussed as follows.

Based on the above calculation results, the customer satisfaction level is evaluated as M1, M6, M3, M9, and M2. M1 shows the best level of customer satisfaction. The reasons are as follows: First is the best performance with accessibility. It was opened in 1984. Therefore, it is convenient for passengers to reach the subway station by bus. Secondly, it has high score in both ticketing service and information service system. The vending machines are sufficient in the station, so it is convenient for passengers to purchase tickets. Thirdly, it has high score in safety. M1 has been operating for 33 years, and it keeps a good safety record. Lastly, it has high score in time. M1 serves between Liuyuan station and Caijing University station. It has 21 stations, and it runs 48 minutes among all stations, with an average of 2.3 minutes per station. Meanwhile, the punctuality rate is above $99 \%$. However, the comfort of the train is very low because it is the most congested line with 7.8 million passengers per day, and the electrical equipment at the station is old. Therefore, the Tianjin Metro needs to increase the number of cars or the starting frequency to reduce the congestion of each car. The worst customer satisfaction level is M2. The reason can be explained as follows: Firstly, it has the worst performances with accessibility. M2 serves between Caozhuang station and Binhai airport station, the line crossing 6 districts, so it is not very convenient for passengers to reach the station by bus. Secondly, it has low score in both ticketing service and information service system. The vending machines are insufficient in the station; in the peak hour, passengers need to line up for tickets. Thirdly, it has low score in time. It has 20 stations, and it runs 41 minutes among all stations, with an average of 2.1 minutes per station. Meanwhile, the punctuality rate is blow $98 \%$. It has high score in train comfort, station comfort, and safety. Since it is a new line, it is not as crowded as the M1.

Moreover, we can find that passengers pay more attention to the safety of the trip (the weight of $\mathrm{C} 17$ is 0.188 ). The finding is supported by the actual situation in China [41, 42]. In China, passengers give priority to urban rail transit that is safe to use. Since China has large amount population in city, the passengers who use urban rail transit are very large. Take the M1 in Tianjin as an example; the volume exceeds 7.8 million passengers per day. The large volume can easily cause accidents. Therefore, the passengers are particularly concerned with the safety. And the security against accidents has a relatively high influence on customer satisfaction; the operator of the urban rail transit should pay more attention to the safety operation. Li et al. [43] pointed out that security against accidents needs more attention. A high level of safety in regard to accidents can promote customer satisfaction and facilitate subsequent reuse. 
On the other hand, the usage of modern equipment inside the train service and cleanliness inside the trains were found to be less significant of all the variables of customer satisfaction. Compared with some case studies in developed countries [19, 34, 44], cleanliness and modern equipment have an important impact on the customer satisfaction. From these, we can see that, compared with passengers in developed countries, passengers in China pay less attention to usage of modern equipment and cleanness in the train; they can tolerate these conditions. These issues can be solved by improving the quality of station environment and providing more modern equipment at stations.

\section{Conclusion}

Currently, China is accelerating the construction of urban rail transit. How to attract more people to choose urban rail transit rather than private car and raise the share ratio of urban rail transit has become a major problem. Therefore, the operator needs to improve the service quality to meet the passengers' needs and enhance passenger satisfaction. The present customer satisfaction evaluation model has not considered multiple participants and the fuzziness of participant evaluation information. Based on the literature review, the urban rail transit evaluation index system was established, and the intuitionistic fuzzy group decision model was applied to the urban rail transit customer satisfaction evaluation model. The application of intuitionistic fuzzy entropy and IFWA aggregation operator in the evaluation of customer satisfaction in urban rail transit is introduced. Finally, the effectiveness of the model is examined through an example.

The overall customer satisfaction level of the urban rail transit lines was determined. Based on the results, it is determined that the line M1 has the best overall customer satisfaction level. Lines M6, M3, and M9 show the second, third, and fourth performance, respectively. The worst customer satisfaction level is line M2.

The contribution of this paper is summarized as follows: (1) On the basis of intuitionistic fuzzy group decision model, we successfully describe the uncertainty of customer satisfaction evaluation and avoid the loss of evaluation information. (2) A fuzzy multicriteria decision-making method based on intuitionistic fuzzy entropy and IFWA aggregation operators is proposed to evaluate the customer satisfaction of Tianjin urban rail transit network. (3) Based on the proposed model, the overall customer satisfaction level of each urban rail transit line is obtained.

\section{Data Availability}

The numerical application data used to support the findings of this study are included within the article.

\section{Conflicts of Interest}

The authors declare that they have no conflicts of interest.

\section{Acknowledgments}

The authors wish to thank the Natural Science Foundation of Tianjin Education Commission (043-135202-JW1717).

\section{References}

[1] N. Aydin, E. Celik, and A. T. Gumus, "A hierarchical customer satisfaction framework for evaluating rail transit systems of Istanbul," Transportation Research Part A: Policy and Practice, vol. 77, pp. 61-81, 2015.

[2] T. Litman, "Evaluating rail transit benefits: A comment," Transport Policy, vol. 14, no. 1, pp. 94-97, 2007.

[3] E. Celik, O. N. Bilisik, M. Erdogan, A. T. Gumus, and H. Baracli, "An integrated novel interval type-2 fuzzy MCDM method to improve customer satisfaction in public transportation for Istanbul," Transportation Research Part E: Logistics and Transportation Review, vol. 58, pp. 28-51, 2013.

[4] K. T. Atanassov, "Intuitionistic fuzzy sets," Fuzzy Sets and Systems, vol. 20, no. 1, pp. 87-96, 1986.

[5] C. Fornell, "A National Customer Satisfaction Barometer: The Swedish Experience," Journal of Marketing, vol. 56, no. 1, pp. 621, 1992.

[6] M. Morfoulaki, Y. Tyrinopoulos, and G. Aifadopoulou, "Estimation of Satisfied Customers in Public Transport Systems: A New Methodological Approach," Journal of the Transportation Research Forum, vol. 46, no. 1, pp. 63-72, 2010.

[7] Y. Tyrinopoulos and C. Antoniou, "Public transit user satisfaction: Variability and policy implications," Transport Policy, vol. 15, no. 4, pp. 260-272, 2008.

[8] S. N. Geetika, "Determinants of Customer Satisfaction on Service Quality: A Study of Railway Platforms in India," Journal of Public Transportation, vol. 13, no. 1, pp. 97-113, 2010.

[9] J. Del Castillo and F. G. Benitez, "A Methodology for Modeling and Identifying Users Satisfaction Issues in Public Transport Systems Based on Users Surveys," Procedia - Social and Behavioral Sciences, vol. 54, no. 2290, pp. 1104-1114, 2012.

[10] M. Diana, "Measuring the satisfaction of multimodal travelers for local transit services in different urban contexts," Transportation Research Part A: Policy and Practice, vol. 46, no. 1, pp. 1-11, 2012.

[11] E. Celik, N. Aydin, and A. T. Gumus, "A multiattribute customer satisfaction evaluation approach for rail transit network: A real case study for Istanbul, Turkey," Transport Policy, vol. 36, pp. 283-293, 2014.

[12] J. L. Machado-León, R. de Oña, T. Baouni, and J. de Oña, "Railway transit services in Algiers: priority improvement actions based on users perceptions," Transport Policy, vol. 53, pp. 175-185, 2017.

[13] J. de Oña, R. de Oña, L. Eboli, and G. Mazzulla, "Heterogeneity in Perceptions of Service Quality among Groups of Railway Passengers," International Journal of Sustainable Transportation, vol. 9, no. 8, pp. 612-626, 2015.

[14] Y. Fu, L. Eboli, G. Mazzulla, and Y. Zhang, "Railway service quality in northern Italy: A multilevel synthetic assessment," Advances in Mechanical Engineering, vol. 9, no. 3, pp. 1-12, 2017.

[15] L. Eboli, C. Forciniti, and G. Mazzulla, "Evaluating spatial association in passengers' perception of rail service quality at stations," Ingegneria Ferroviaria, vol. 73, no. 2, pp. 125-142, 2018. 
[16] L. Eboli and G. Mazzulla, "Relationships between rail passengers' satisfaction and service quality: a framework for identifying key service factors," Public Transport, vol. 7, no. 2, pp. 185201, 2015.

[17] R. Agarwal, "Public Transportation and Customer Satisfaction: The Case of Indian Railways," Global Business Review, vol. 9, no. 2, pp. 257-272, 2008.

[18] C. Cao and J. Chen, "An empirical analysis of the relationship among the service quality, customer satisfaction and loyalty of high speed railway based on structural equation model," Canadian Social Sciences, vol. 7, no. 4, pp. 67-73, 2011.

[19] K. R. Stuart, M. Mednick, and J. Bockman, "Structural equation model of customer satisfaction for the New York city subway system," Transportation Research Record, no. 1735, pp. 133-137, 2000.

[20] P.-F. Chou, C.-S. Lu, and Y.-H. Chang, "Effects of service quality and customer satisfaction on customer loyalty in high-speed rail services in Taiwan," Transportmetrica A: Transport Science, vol. 10, no. 10, pp. 917-945, 2014.

[21] W. Shen, W. Xiao, and X. Wang, "Passenger satisfaction evaluation model for Urban rail transit: A structural equation modeling based on partial least squares," Transport Policy, vol. 46, pp. 20-31, 2016.

[22] V. Yilmaz and E. Ari, "The effects of service quality, image, and customer satisfaction on customer complaints and loyalty in high-speed rail service in Turkey: a proposal of the structural equation model," Transportmetrica A: Transport Science, vol. 13, no. 1, pp. 67-90, 2017.

[23] L. A. Zadeh, "Fuzzy sets," Information and Computation, vol. 8, pp. 338-353, 1965.

[24] K. T. Atanassov, "More on intuitionistic fuzzy sets," Fuzzy Sets and Systems, vol. 33, no. 1, pp. 37-45, 1989.

[25] W. Yang and Z. Chen, "The quasi-arithmetic intuitionistic fuzzy OWA operators," Knowledge-Based Systems, vol. 27, pp. 219-233, 2012.

[26] D.-F. Li, “The GOWA operator based approach to multiattribute decision making using intuitionistic fuzzy sets," Mathematical and Computer Modelling, vol. 53, no. 5-6, pp. 1182-1196, 2011.

[27] Z. S. Xu and R. R. Yager, "Intuitionistic and interval-valued intuitionistic fuzzy preference relations and their measures of similarity for the evaluation of agreement within a group," Fuzzy Optimization and Decision Making, vol. 8, no. 2, pp. 123-139, 2009.

[28] C. Tan and X. Chen, "Induced intuitionistic fuzzy Choquet integral operator for multicriteria decision making," International Journal of Intelligent Systems, vol. 26, no. 7, pp. 659-686, 2011.

[29] Z. S. Xu and Q. L. Da, "The ordered weighted geometric averaging operators," International Journal of Intelligent Systems, vol. 17, no. 7, pp. 709-716, 2002.

[30] Z.S. Xu and R. R. Yager, "Some geometric aggregation operators based on intuitionistic fuzzy sets," International Journal of General Systems, vol. 35, no. 4, pp. 417-433, 2006.

[31] W. Wang and X. Liu, "Intuitionistic fuzzy geometric aggregation operators based on einstein operations," International Journal of Intelligent Systems, vol. 26, no. 11, pp. 1049-1075, 2011.

[32] M. Brons, M. Givoni, and P. Rietveld, "Access to railway stations and its potential in increasing rail use," Transportation Research Part A: Policy and Practice, vol. 43, no. 2, pp. 136-149, 2009.

[33] G. Vuk, "Transport impacts of the Copenhagen Metro," Journal of Transport Geography, vol. 13, no. 3, pp. 223-233, 2005.
[34] E. Nathanail, "Measuring the quality of service for passengers on the hellenic railways," Transportation Research Part A: Policy and Practice, vol. 42, no. 1, pp. 48-66, 2008.

[35] N. Aydin, "A fuzzy-based multi-dimensional and multi-period service quality evaluation outline for rail transit systems," Transport Policy, vol. 55, pp. 87-98, 2017.

[36] Z. Xu, "Intuitionistic preference relations and their application in group decision making," Information Sciences, vol. 177, no. 11, pp. 2363-2379, 2007.

[37] H. Gerçek, B. Karpak, and T. Kilinçaslan, "A multiple criteria approach for the evaluation of the rail transit networks in Istanbul," Transportation, vol. 31, no. 2, pp. 203-228, 2004.

[38] Z. Xu, "Intuitionistic fuzzy aggregation operators," IEEE Transactions on Fuzzy Systems, vol. 15, no. 6, pp. 1179-1187, 2007.

[39] I. K. Vlachos and G. D. Sergiadis, "Intuitionistic fuzzy information-applications to pattern recognition," Pattern Recognition Letters, vol. 28, no. 2, pp. 197-206, 2007.

[40] B. Liu, T. Huo, X. Wang, Q. Shen, and Y. Chen, “The decision model of the intuitionistic fuzzy group bid evaluation for urban infrastructure projects considering social costs," Canadian Journal of Civil Engineering, vol. 40, no. 3, pp. 263-273, 2013.

[41] H. Sun, Y. Zhang, Y. Wang, L. Li, and Y. Sheng, "A social stakeholder support assessment of low-carbon transport policy based on multi-actor multi-criteria analysis: The case of Tianjin," Transport Policy, vol. 41, pp. 103-116, 2015.

[42] H. Pan, Q. Shen, and S. Xue, "Intermodal transfer between bicycles and rail transit in Shanghai, China," Transportation Research Record, no. 2144, pp. 181-188, 2010.

[43] Q. Li, L. Song, G. F. List, Y. Deng, Z. Zhou, and P. Liu, "A new approach to understand metro operation safety by exploring metro operation hazard network," Safety Science, vol. 93, pp. 5061, 2017.

[44] L. Eboli and G. Mazzulla, "Structural equation modelling for analysing passengers' perceptions about railway services," Procedia: Social and Behavioral Sciences, vol. 54, pp. 96-106, 2012. 


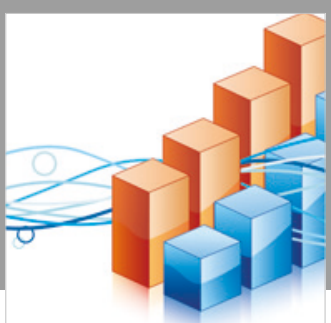

Advances in

Operations Research

\section{-n-m}
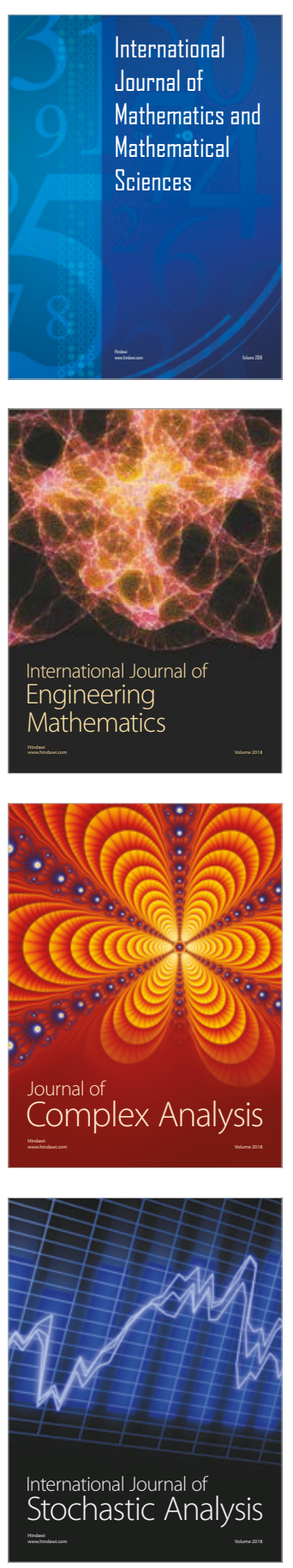
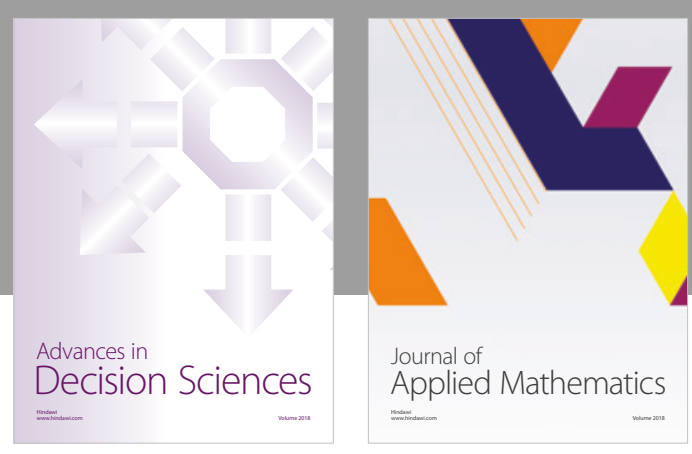

Journal of

Applied Mathematics
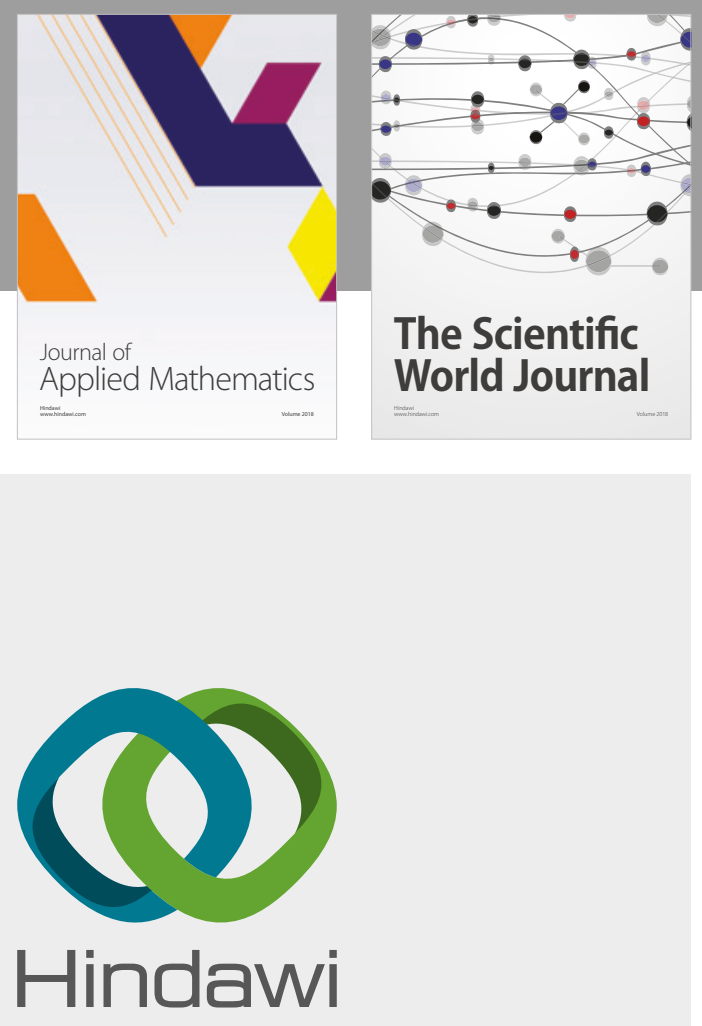

Submit your manuscripts at

www.hindawi.com

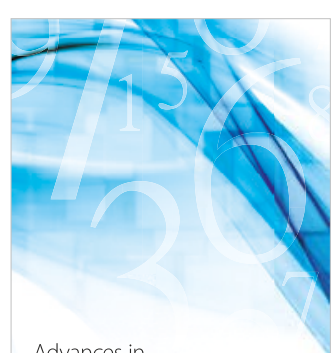

Advances in
Numerical Analysis
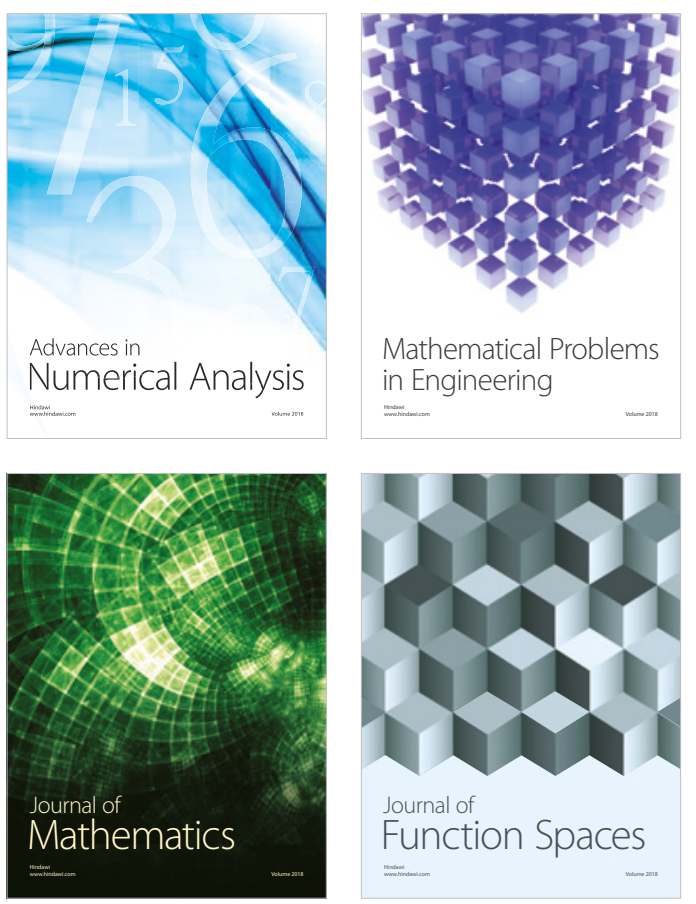

Mathematical Problems in Engineering

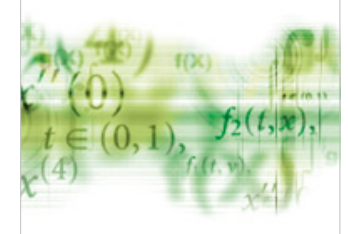

International Journal of

Differential Equations

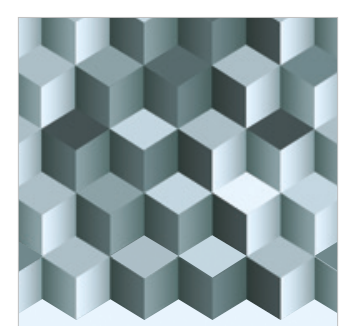

Journal of

Function Spaces

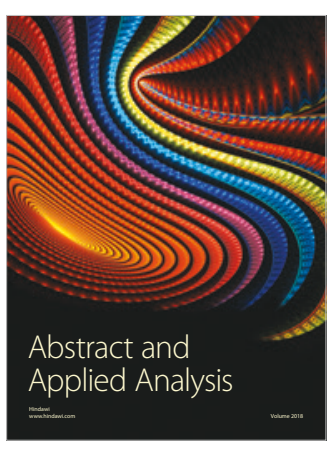

The Scientific

World Journal

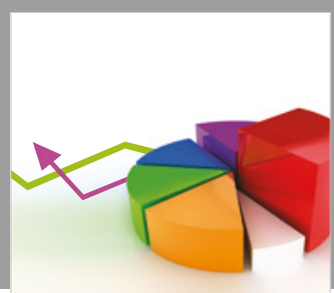

Journal of

Probability and Statistics
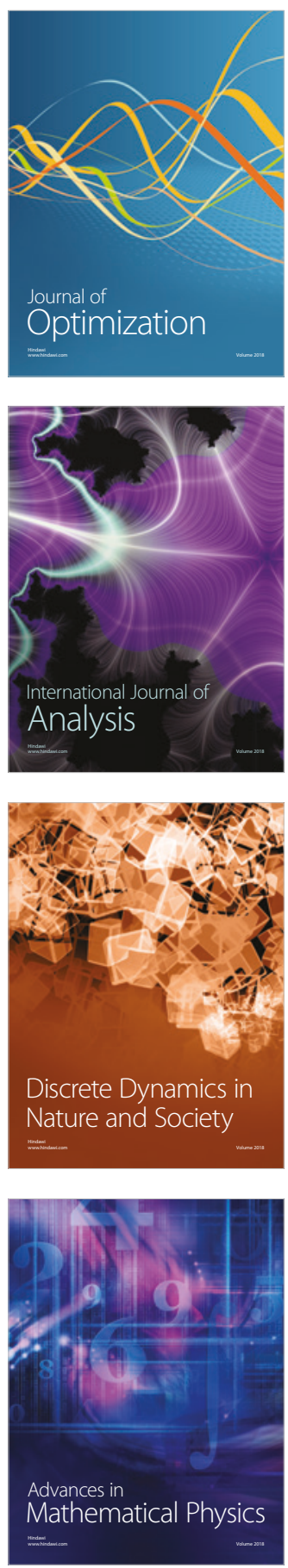